\title{
EVALUATION OF STOCK MANAGEMENT STRATEGIES RELIABILITY AT DEPENDENT DEMAND
}

\author{
Valery Lukinskiy ${ }^{1}$, Vladislav Lukinskiy ${ }^{2}$ \\ ${ }^{1,2}$ National Research University Higher School of Economics (HSE) \\ St. Petersburg, Russia \\ Ph.: 007(812)644-59-11(+61517) \\ 'e-mail:lukinskiy@mail.ru \\ 2e-mail:vladas27@mail.ru
}

\begin{abstract}
For efficiently increasing the logistic systems, the core specialists' attention has to be directed to reducing costs and increasing supply chains reliability. A decent attention to costs reduction has already been paid, so it can be stated that in this way there is a significant progress. But the problem of reliability evaluation is still insufficiently explored, particularly, in such an important sphere as inventory management at the dependent demand.

In the article there is a suggested methodical approach that allows calculating the safety stock quantity at the dependent demand in view of supply chains reliability requirements; the variants for different inventory management strategies at the dependent demand are examined; optimal strategy choice algorithm and results of total costs calculation in view of the reliability are given.
\end{abstract}

Keywords: supply chains reliability, inventory management, dependent demand, perfect order

\section{Introduction}

The publications analysis has allowed to reveal the opinions of several authors about features of stocks management at dependent demand. In their works the majority of authors examine the answers to the following questions.

What is MRP? Material requirements planning (MRP) is a computerized information system developed specifically to help manufacturers manage dependent demand inventory and schedule replenishment orders (Krajewski et al., 2013). "Dependent demand" means the demand for one item is related to the demand for another item. The dependent technique used in a production environment is called material requirements planning (MRP) (Heizer and Render, 2011). Controlling or managing inventory is one of the most important aspects of operations and is certainly value enhancing for the firm. Firms can and typically do have some sort of material requirements planning (MRP) software system for managing their inventory. MRP was first developed in the 1960s. MRP is a system that has been used widely by manufacturing firms for computing dependent demand and timing requirements (Wisner et al., 2012). Material requirements planning (MRP) is a materials planning method that is based on the points in the time when net requirement of materials arises, i.e. when future calculated stock availability becomes negative (Jonsson, 2008). Originally popularized by Joseph Orlicky, MRP deals specifically with supplying materials and component parts whose demand depends upon the demand for a specific end product (Coyle et al., 2003). In the early days of production planning and control a single concept and software system was applied in industry - material requirements planning (MRP) - irrespective of many different requirements existing in diverse areas such as the production of foods or automobiles. On the other hand, if a production manager was asked whether the production system he manages is unique and requires special purpose decision-making tools, most probably the answer would be "yes". As regards the type of decisions to be made, the truth lies somewhere in the middle of these two extremes (Stadtler and Kilger, 2008). MRP is a method primarily used for scheduling high-valued custom-made parts, materials, and supplies whose demand is reasonable well known. The purpose of MRP, from a logistics viewpoint, is to avoid, as much as possible, carrying these items in inventory (Ballou, 1999). It is very common that the demand for an item depends on the demand for some other items. Consider, for example, an item that is used exclusively as a component when assembling some final products. It is then often natural to first forecast the demand for these final products, for example by extrapolation of historical data. Next we determine a production plan for the products. The demand for the considered component is then obtained directly from the production plan. This technique to "forecast" demand for the dependent items is used in Material Requirement Planning (MRP). It is most common to use MRP in production. But since a product 
structure corresponds to a multi-echelon inventory system, we can also use the same ordering technique in a distribution system (Axsäter, 2006).

What are advantages of MRP systems using? Many firms have found important benefits in MRP. These benefits include (1) better response to customer orders as the result of improved adherence to schedules, (2) faster response to market changes, (3) improved utilization of facilities and labor, and (4) reduced inventory levels (Heizer and Render, 2011). Theoretically, inventories do not need to be created when the amount and timing of the end-product requirements are known. Precise timing of materials flows to meet production requirements is the principle behind MRP (Ballou, 1999). The major advantage of MRP is that it enables us to keep track of relatively infrequent large requirements (Axsäter, 2006).

What conditions exist for MRP application? Effective use of dependent inventory models requires that the operations manager know the following:

1. Master production schedule (what is to be made and when);

2. Specifications or bill of material (materials and parts required to make the product);

3. Inventory availability (what is in stock);

4. Purchase orders outstanding (what is on order, also called expected receipts);

5. Lead time (how long it takes to get various components) (Heizer and Render, 2011).

Lead times are not likely to be known for sure. When to release the request for materials depends on the uncertainty in lead time as it affects over- and understocking (balancing the expected cost associated with having the materials arrive before they are needed, thereby incurring a holding charge with the expected cost of having the materials arrive after they are needed, thereby incurring a late penalty charge) (Ballou, 1999). Usually the requirements as well as the deliveries are assumed to occur in the beginning of a period (Axsäter, 2006).

What disadvantages do the MRP systems have? For years, many companies tried to manage production and their dependent demand inventories using independent demand systems, but the outcome was seldom satisfactory because dependent demand is fundamentally different from independent demand (Krajewski et al., 2013). Because there is often a rush to get a new product to market, however, drawings and bill of material (BOM) may be incomplete or even nonexistent. Moreover, complete drawings and BOMs (as well as other forms of specifications) often contain errors in dimensions, quantities, or countless other areas. When errors are identified, engineering change notices (ECNs) are created, further complicating the process. With MRP, the operations manager can react to the dynamics of the real world. Moreover, if the nervousness is caused by legitimate changes, then the proper response may be to investigate the production environment - not adjust via MRP (Heizer and Render, 2011). A key benefit of MRP is that production information is available for the entire planning horizon; thus, it provides visibility for schedulers to plan ahead. However, the need for offsetting net requirements by the lead time to obtain planned order releases causes a loss of visibility in the planning horizon of components. This problem is especially acute for products with a deep bill of materials. Another drawback of the MRP is that it ignores capacity and shop floor conditions (Wisner et al., 2012). Shortcomings of MRP-based approaches include the following. Their application is computer intensive, and making changes is sometimes difficult once the system is in operation. Both ordering and transportation costs may rise as a firm reduces inventory levels and possibly moves toward a more coordinated system of ordering product in smaller amounts to arrive when the firm needs it. They are not usually as sensitive to short-term fluctuations in demand as are order point approaches (although they are not as inventory intensive, either). They frequently become quite complex and sometimes do not work exactly as intended (Coyle et al., 2003). Time-phased secondary demands are a prerequisite for generating production or replenishment orders so that demands for finished products can be met in time with as little work-in-process and inventory as possible. Although most appealing, this logic suffers from ignoring available capacities. Consequently, production orders may result in overloaded capacities and thus infeasibilities (Stadtler and Kilger, 2008). Because of the intermittent depletions of the component inventory, high inventory levels must be maintained when they are not needed. If the rate of depletion of the inventory level can even roughly be anticipated, components may be ordered just ahead of the depletion with resulting substantial savings in inventory carrying costs (Ballou, 1999). One problem with MRP can be that the plans for individual items change too frequently over time. Even a very small change in the master production schedule can lead to relatively large changes in the plans for many lower level items. This "instability" of MRP is often called "nervousness". One possibility to reduce the nervousness is to "freeze" orders within a certain time frame. This means that orders within this time frame are not changed according to the MRP logic. The MRP logic is simple, yet the computational effort can be very large if there are thousands of items and complex multi-level product structures (Axsäter, 2006).

What are the reasons for creating safety stock at the dependent demand? At important managerial decision is the quantity of safety stock to carry. It is more complex for dependent demand items than for 
independent demand items. Safety stock for dependent demand items with lumpy demand (gross requirements) is helpful only when future gross requirements, the timing or size of scheduled receipts, and the amount of scrap that will be produced are uncertain. As these uncertainties are resolved, safety stock should be reduced and ultimately eliminated (Krajewski et al., 2013). The continuing task of operations managers is to remove variability. Realistically, however, managers need to realize that bill of material and inventory records, like purchase and production quantities, as well as lead times, may not be perfect. This means that some consideration of safety stock may be prudent. Because of the significant domino effect of any change in requirements, safety stock should be minimized, with a goal of ultimate elimination. When safety stock is deemed absolutely necessary, the usual policy is to build it into the projected on-hand inventory of the MRP logic. Distortion can be minimized when safety stock is held at the finished goods level and at the purchased component or raw material level (Heizer and Render, 2011). Dependent demand may have a pattern of abrupt and dramatic changes because of its dependency on the demand of the final product, especially if the final product is produced in large lot sizes. Safety stock protects against uncertainties in demand, supply, quality and lead time (Wisner et al., 2012). Protection against uncertainty in the requirements and supplies that are part of material requirements planning can be achieved with the aid of safety stock and safety time (Jonsson, 2008). It seems wise to include "some" safety time into the leadtime offset of uncritical operations that is the direct predecessor of a critical operation (Stadtler and Kilger, 2008). End-product requirements are assumed to be known for sure, as are lead times. Even though certainty is assumed, the effects of uncertainty in the requirements levels and in the lead times are always presents. Transport rate breaks may alter the order release quantity (Ballou, 1999). Safety stocks are used to cover variation in demand and lead-times. When applying MRP it is also common to use a safety time as an alternative or supplement. This means that we plan the orders so that the deliveries are expected to occur the safety time before the corresponding net requirements (Axsäter, 2006).

What approaches for safety stock quantity definition exist in the MRP systems? Buckets are time units in an MRP system. Reduce MRP "buckets" from weekly to daily to perhaps hourly (Heizer and Render, 2011). Safety stocks can be incorporated in the MRP logic by using the following rule: schedule a planned receipt whenever the projected on-hand inventory balance drops below the desired safety stock level (rather than zero, as before). The objective is to keep a minimum level of planned inventories equal to the safety stock quantity (Krajewski et al., 2013). Its implication in MRP logic is that the minimum projected on-hand inventory should not fall below the safety stock level (Wisner et al., 2012). If safety stocks are used, the starting stock availability is reduced by the selected safety stock quantity before the calculation of net requirements is started. If safety time is used instead, the point in time of delivery for the planned order is the same as the calculated requirement time minus the selected safety time (Jonsson, 2008). The MRP approach to purchase timing assumes that the requirements in the master schedule are known. To the extent that they may vary throughout the planning horizon, some safety stock protection is needed if the requirements are to be met. If the variability in requirements can be represented by a probability distribution, then the amount of safety stock needed in the schedule can be determined in a way that is similar to inventory control. However, this may be impractical, because the requirements for any product or component are likely to show wide variations due to changes in production schedules, cancelled customer orders, and missed forecasts. This will lead to inaccurate estimates of the safety stock levels. As an alternative, a fixed on hand-inventory level can be maintained that is determined by practical experience or some other means. Although this method is approximate, it is probably the best that can be done considering the inherent lumpy nature of derived demand (Ballou, 1999). The most common convention when determining the net requirement is to require that backorders plus the safety stock should be covered. We can interpret the planning of orders as the application of an installation stock reorder point system, where the reorder point is the lead-time demand plus the safety stock minus one (the projected inventory should be larger or equal to the safety stock). The lead-time in the MRP system is a planning parameter that does not necessarily need to correspond to an estimate of the real lead-time. If we set the lead-time to zero, the reorder point is constant and equal to the safety stock minus one. The safety stock is also a planning parameter that can be chosen arbitrarily (Axsäter, 2006).

Where does the safety stock have to be located? The usual policy is to use safety stock for end items and purchased items to protect against fluctuating customer orders and unreliable suppliers of components but to avoid using it as much as possible for intermediate items (Krajewski et al., 2013). One may ask what reasons there are for generating an alert during the BOM explosion. Obviously, if we started from an infeasible production plan, e.g. with backlogging, then the BOM explosion would also generate alerts showing that some materials are not ready in time. At this stage a popular counter measure would be expediting, resulting in reduced lead-times. A second reason for a mismatch of a (feasible) production plan and the result of a BOM explosion may be that lead-times used in Production Planning 
are independent of the amount produced, while in a BOM explosion lead-times can be calculated based on the order size. Again, any discrepancy jeopardizing efficiency or feasibility should be shown to the decision maker by an alert (Stadtler and Kilger, 2008). In practice there are usually several ways to avoid the shortage. Perhaps it is possible to temporarily reduce the lead-time. Another alternative is to adjust the basis for the planning. It may, for example, be possible to change the master production schedule or to adjust order quantities and safety stocks (Axsäter, 2006). Knowledge of what is in stock is the result of good inventory management. Good inventory management is an absolute necessity for an MRP system to work. If the firm does not exceed $99 \%$ record accuracy, then material requirements planning will not work. Record accuracy of $99 \%$ may sound good, but note that even when each component has an availability of $99 \%$ and a product has only seven components, the likelihood of a product being completed is only .932 (because $.99^{7}=0.932$ ) (Heizer and Render, 2011).

Summarizing the sources where parameters calculation examples of different planning strategies of inventory quantity at the dependent demand are given, the following can be stated:

1. Planned periods duration, for which the calculation is executed, fluctuates from 6 to 12 weeks.

2. Minimal and maximal stock quantities in each planned period cover the wide range of values, for example, from 20 to 100 products (Axsäter, 2006), from 0 to 50 products (Leenders and Fearon, 1997).

3. To choose the best strategy using the economic criteria the two costs types are used: for the order implementation and for stock holding.

4. Safety stock quantity is mentioned in two works (Axsäter, 2006; Lysons and Gillingham, 2003), but there are no instructions for their determining method.

5. The number of stock quantity strategies and their periodicity planning fluctuates from one to six; the most often indicated strategies are LFL, EOQ and LTC, but there are not any instructions for the most appropriate strategy.

Thus, in spite of having several strategies (lot-for-lot - LFL; least total cost - LTC; least unit cost - LUC; part-period balancing - PPB, Silver-Meal algorithm, Groff's method etc.) for dependent demand management, all of them are intended to calculate the current stock parameters. Other indexes, for example, probabilistic evaluation of safety stock, deficit, functioning reliability of all stock management system practically are not considered. This problem becomes even more vexed at supplying the component parts (items, details etc.) that cannot be made at this enterprise.

\section{The Probabilistic Model Forming for the Safety Stock Parameters Calculation at the Dependent Demand}

Summarizing and analysis of different approaches for the supply indexes calculation at the dependent demand have allowed making the hypothesis: the perfect order fulfillment should be used for the items stock reliability evaluation.

The perfect order concept (Perfect Order Fulfillment, POF) is being used more and more actively in the logistics and supply chains management because it reflects the most important consumer requirement to the service quality (Stock and Lambert, 2001).

POF means the faultless execution of all order cycle operations according to the contract terms. Another definition says that POF is a percent of executed orders quantity which correspond to all requirements of shipping, documents preparation and defect absence.

Number of operations (factors) included into POF fluctuates in wide range (from 2 to 11), however, the most often used model is that one which includes order readiness (accuracy in quantity and quality of nomenclatures in order), reliable execution (paper filling accuracy) and delivery timeliness.

Nowadays there are different approaches of POF quantitative evaluation. The most popular variant for the probability calculation of $P_{o}$ reliable order execution looks like (Christopher, 2011; Ballou, 1999)

$$
P_{o}=\prod_{i=1}^{n} P_{i}
$$

where $P_{i}$ is probability of reliable execution of i-operation;

$n$-is a number of operations (factors) included in the perfect order.

In the work (Lukinskiy V.S. and Lukinskiy V.V., 2015) another POF evaluation approach is suggested, it is based on the general theorem of repeated experiments.

According to this theorem while conducting $n$ independent experiments there is a probability of some $A_{i}$ event appearing or not appearing in each experiment. The appearing probability of $A$ event in $i$-th 
experiment equals $p_{i}$, not appearing probability is $q_{i}=1-p_{i}(i=1, \ldots, n)$. In probability theory works, for instance (Ventsel and Ovcharov, 1983), it is shown that for $P_{m, n}$ probability calculation reflecting $A$ event appearing $m$ times in $n$ experiments the following formula can be used:

$\prod_{i=1}^{n}\left(q_{i}+p_{i} z\right)=\sum_{m=0}^{n} P_{m, n} z^{m}$

where $z$ is a random parameter.

After brackets opening in the left part of equation (2) and cancelling like terms with different $z^{m}$, we will find the probabilities $P_{o, n}, P_{1, n}, \ldots, P_{m, n}$, i.e. the probability of perfect order forming at the different number of simultaneously observed $m$ signs of failure.

For example, for $n=2$ we have

$\prod_{i=1}^{n}\left(q_{i}+p_{i} z\right)=q_{1} q_{2}+\left(q_{1} p_{2}+q_{2} p_{1}\right) z+p_{1} p_{2} z^{2}$

Thereafter, for $n=3$

$\prod_{i=1}^{n}\left(q_{i}+p_{i} z\right)=q_{1} q_{2} q_{3}+\left(p_{1} q_{2} q_{3}+q_{1} p_{2} q_{3}+q_{1} q_{2} p_{3}\right) z+\left(q_{1} p_{2} p_{3}+p_{1} q_{2} p_{3}+p_{1} p_{2} q_{3}\right) z^{2}+p_{1} p_{2} p_{3} z^{3}$.

The first addend in formulas (3), (4) reflects the probability of failures absence, i.e. reliable order implementation; the last addend reflects the probability of simultaneous appearing of all factors.

Next step which will allow dependent demand indexes calculating is statistic parameters definition in view of the chosen distribution law. Considering the fact that failure presence at the examined order belongs to the rare events, let's presume, that for their quantitative description the discrete distribution can be used: binomial, geometric, Poisson and others (Table 1).

Let us examine the sequence of dependent demand indexes calculation. We presume that planned component order quantity equals $N$. Taking into account (2)-(4), the mean quantity of order without defect and mistakes will be:

$A=N \cdot q_{0}=N \cdot \prod_{i=1}^{n} q_{i} \cdot$

Similarly to the independent demand $A$ quantity can be examined as a current stock.

To calculate of mean and standard deviation of defected products number we will use formulas for binomial distribution:

$\bar{Q}=N\left(1-q_{0}\right)$,

and

$\sigma_{Q}=\sqrt{N \cdot q_{0}\left(1-q_{0}\right)}$.

With $N \rightarrow \infty$ the binomial distribution tends to the normal one (Ventsel and Ovcharov, 1983). So, with large $N$ defected products distribution function can be approximately determined using the normal distribution with parameters calculated by formulas (6) and (7).

Table 1. Basic characteristics of discrete distribution laws

\begin{tabular}{|l|l|l|l|l|l|}
\hline $\begin{array}{c}\text { Type of } \\
\text { distribution }\end{array}$ & Parameters & $\begin{array}{c}\text { Random } \\
\text { variables values }\end{array}$ & \multicolumn{1}{|c|}{ Probability } & Mean value & Dispersion \\
\hline Binomial & $\mathrm{n}, \mathrm{p}, \mathrm{q})$ & $\mathrm{m}=0,1 \ldots, \mathrm{n}$ & $P_{m, n}=C_{n}^{m} p^{m} q^{n-m}$ & $n p$ & $n p q$ \\
\hline Geometric & $\mathrm{n}, \mathrm{p},(\mathrm{q})$ & $\mathrm{m}=0,1,2 \ldots$ & $P_{m}=p q^{m-1}$ & $1 / p$ & $q / p^{2}$ \\
\hline Poisson & $\mathrm{a}$ & $\mathrm{m}=0,1,2 \ldots$ & $P_{m}=\frac{a^{m}}{m !} e^{-a}$ & $a$ & $a$ \\
\hline Hypergeometric & $\mathrm{N}, \mathrm{p}, \mathrm{n}, \mathrm{M}$ & $\mathrm{m}=0,1 \ldots, \mathrm{n}$ & $P_{m, n}=\frac{C_{M}^{m} C_{N-M}^{n-m}}{C_{N}^{n}}$ & $n p$ & $(n p q) \times\left(1-\frac{n-1}{N-1}\right)$ \\
\hline
\end{tabular}


Then the safety stock calculation, which is necessary for the deficit covering of component products, can be done by formula:

$Q_{s}=\bar{Q}+x_{p} \sigma_{Q}$,

where $x_{p}$ is a coefficient (quantile) of normal distribution law corresponding to the chosen (or set) $P_{Q}$ probability.

When several consequent planned periods merge in one period, the safety stock calculation formula looks like:

$Q_{s s}(k)=\sum_{i=1}^{k} \overline{Q_{s i}}+x_{p} \sqrt{q_{0}\left(1-q_{0}\right)} \sqrt{\sum_{i=1}^{k} N_{i}}$,

where $k$ is a number of consequent periods merged in one.

As the alternative to the binomial distribution law to calculate $Q_{s}$ for little $N$, the Poisson distribution can also be used (see Table 1), parameters for which are calculated by formula (6), i.e. $a=\bar{Q}$.

Since the Poisson distribution function is defined with a formula

$F_{m}^{*}=\sum_{m=0}^{n} \frac{a^{m}}{m !} e^{-a}$

then, for the $m$ safety stock quantity definition, the inverse problem is solved. $F_{m}^{*}$ probability is set and on the basis of formula (10) we can find such values for $F_{m}$ and $F_{m+1}$ so as they satisfy the inequality

$F_{m} \leq F_{m}^{*} \leq F_{m+1}$

Let us try to evaluate the item supply reliability at dependent demand. On the basis of the reliability theory, the given supply can be examined as a link in a form of parallel elements combination, one of which is a current stock (reliability probability equals $q_{0}$, formula 5), and another one is safety stock (reliability probability $P_{Q}$ ).

Reliability calculation of such link is executed by the formula:

$P=1-\left(1-q_{0}\right)\left(1-P_{Q}\right)=1-\left(1-\prod_{i=1}^{n} q_{i}\right)\left(1-P_{Q}\right)$.

Apparently, when supplies are being planned as separate components sequence in one period (for example, several weeks) the reliability evaluation formula (12) in the form of reliability probability (nondeficiency) for the whole period looks like:

$P=\prod_{j=1}^{r} P_{j}=\prod_{j=1}^{r}\left(1-\left(1-q_{0 j}\right)\left(1-P_{Q j}\right)\right)$,

where $q_{0 j}$ is reliable $j$-th supply probability;

$P_{0 j}$ is reliable $j$-th supply safety order probability;

$r$ is a number of supplies in the planned period.

\section{Inventory Management Strategies Clarification at Dependent Demand in View of Safety Stocks}

The inventory management strategies at the dependant demand can be symbolically divided into two main groups. The first one is the empirical strategies based on grouping without considering the stock holding costs. Three strategies belong to them: LFL, FOQ and POQ. When we say 'grouping', we mean the union of demands in a unit of some consecutive periods. So, when we use the LFL strategy, we consider single (independent supplies) according to the demands in every period; the FOQ strategy stipulates supply quantity constancy during the whole planned period (at the same time, supply periodicity varies); the POQ strategy stipulates a variable supply quantity at fixed periodicity.

The second group is the economic strategies which use optimization algorithms of supply consignment forming considering supply costs (or starting-up and adjustment works) and stock holding. 
The three most wide-spread strategies - LUC, LTC and Silver-Meal algorithm - are similar according to the employing procedure: the search and determination of the local groupings indexes in a form of supply units during the planned period according to the costs minimum criteria.

In this way, the dependency for the unit costs evaluation in view of safety stocks (LUC strategy) is recorded in the following way:

$C_{u}(k)=\left[C_{o r}+C_{h} \sum_{i=1}^{k}(i-1) N_{i}+C_{h} Q_{s s}(k)\right] / \sum_{i=1}^{k} N_{i} \rightarrow \min$,

where $C_{u}(k)$ is the unit costs for unit which includes $k$ of consecutive periods supplies in a volume of $N_{i}$, $k=1,2, \ldots$;

$C_{o r}$ is the costs for the order and starting-up and adjustment works;

$C_{h}$ is the costs for the product unit holding during the time unit, for example, during a week;

$N_{i}$ is a planned requirement (supply) in $i$-th period;

$Q_{s s}(k)$ is safety stock for $k$-th periods (formula 9).

If in formula (14) we exchange $\sum_{i=1}^{k} N_{i}$ for $k$, we will get the main estimated dependency for the Silver-Meal algorithm.

The distinction of the LTC strategy from the examined above ones lies in the fact that the choice criteria of the estimated $k$ periods quantity and, accordingly, the total volume of a supply unit $\sum_{i=1}^{k} N_{i}$ is formed as a difference of order costs and holding costs

$\Delta_{k}=\mid C_{o r}-\left[\left(C_{h} \sum_{i=1}^{k}(i-1) N_{i}+C_{h} Q_{s s}(k)\right] \mid \rightarrow \min \right.$.

According to the (15) dependency, at $\Delta_{k} \rightarrow \min$ the quantity $\sum_{i=1}^{k} N_{i}$ is regarded as a supply for $k$ periods.

We have to emphasize that the EOQ model which allows to define the indexes of the inventory management of dependent demand in view of the whole planned period duration must be attributed to the economic strategies.

On the basis of offered approaches the general algorithm of inventory management (IM) strategy choice at dependent demand has been formed which includes the evaluations of efficiency (the order and storage costs of current and safety stocks) and reliability of supply chains during the planned period (Fig. 1).

\section{Approbation of Worked out Methodical Approach}

Some calculations for the number of strategies have been carried out to approbate the worked out methodical approach.

Initial data about the planned items need is shown in Table 2.

Table 2. Planned need for stocks during the planned period

\begin{tabular}{|l|c|c|c|c|c|c|c|c|}
\hline Week & 1 & 2 & 3 & 4 & 5 & 6 & 7 & 8 \\
\hline Planned need, $\mathrm{N}_{\mathrm{i}}$, un. & 50 & 70 & 80 & 60 & 40 & 75 & 45 & 60 \\
\hline
\end{tabular}

Apart from the need, the following has been accounted in the calculations:

- Costs for order $\mathrm{C}_{\text {or }}$ are 1200 c.u.

- Holding costs for product unit per week $\mathrm{C}_{\mathrm{h}}-2$ c.u./week.

- Probability of supply quantity accuracy $\mathrm{p}_{1}=0,97$.

- $\quad$ Probability of supply quality accuracy $\mathrm{p}_{2}=0,98$.

- Probability of deficit absence $\mathrm{P}_{\mathrm{Q}}=0,95$ (quantile $\mathrm{x}_{0,95}=1,645$ ).

In Tables 3-7 there are the calculation results for the following strategies: LFL, POQ, LTC, LUC. 


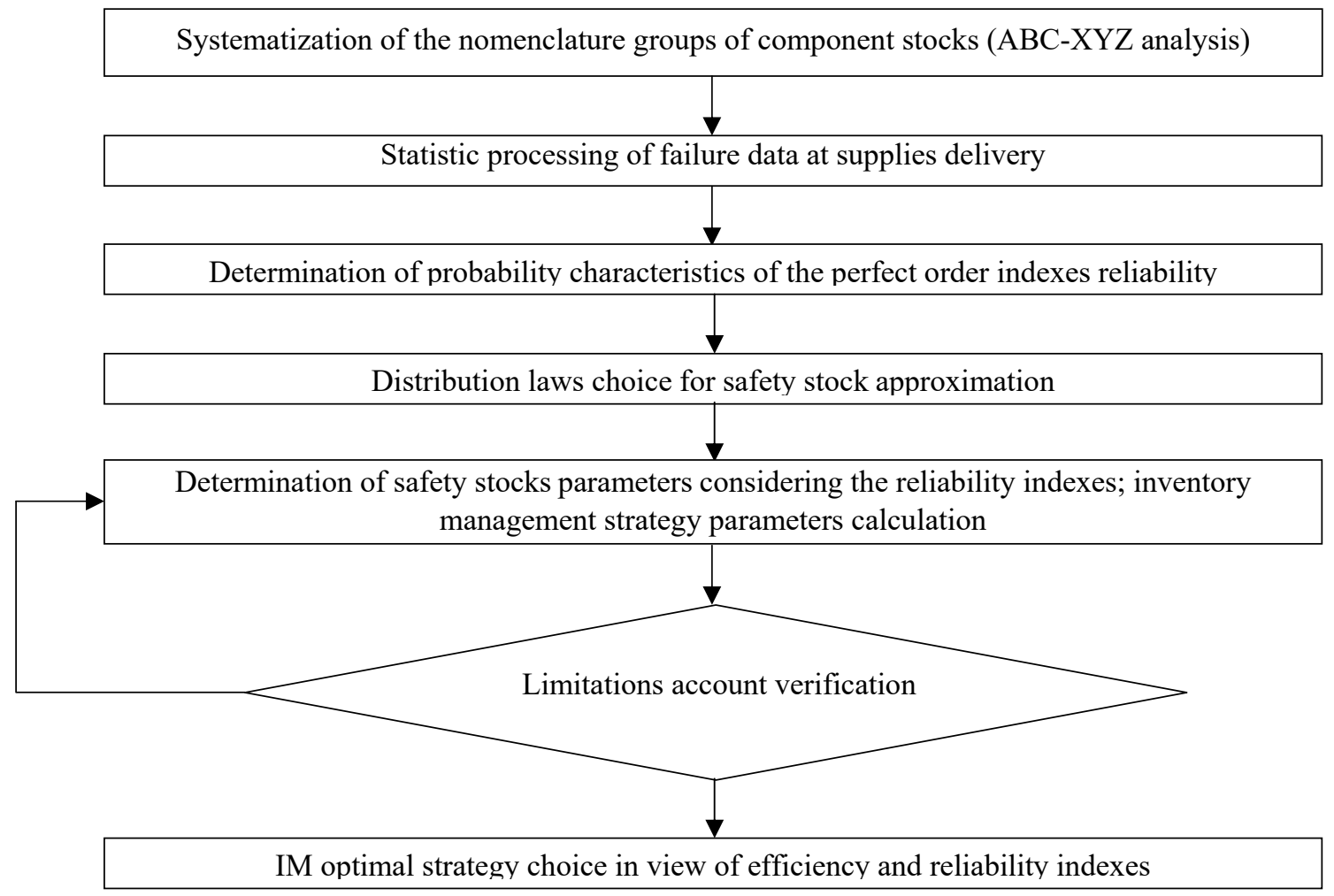

Figure 1. Inventory management optimal strategy choice algorithm at dependent demand

To compare, let's calculate supply indexes according to the EOQ model:

- optimal supply consignment

$$
Q=\sqrt{\frac{2 \cdot 480 \cdot 1200}{2 \cdot 8}}=268 \mathrm{un} \text {. }
$$

- supply number

$$
k=480 / 268 \approx 2 ;
$$

- total costs (current stock)

$$
C_{\Sigma}=\sqrt{2 \cdot 480 \cdot 1200 \cdot 16}=4293 \text { c.u.; }
$$

- safety stock, formula (9)

$$
Q_{s s}=268 \cdot 0,05+1,645 \sqrt{0,05 \cdot 0,95} \cdot \sqrt{268}=19 \text { units; }
$$

- safety stock holding costs

$$
C_{s s}=2 \cdot 19 \cdot 4,5=171 \text { c.u. }
$$

- supply reliability probability during the planned period $(\mathrm{r}=2)$, formula (13)

$$
P=[1-(1-0,95)(1-0,95)]^{2}=0,995
$$

Table 3. Consignments quantity evaluation based on LFL (Lot for Lot) strategy

\begin{tabular}{|c|c|c|c|c|c|}
\hline Week & $\begin{array}{c}\text { Planned need, } N_{i}, \\
\text { un. }\end{array}$ & $\begin{array}{c}\text { Order costs, } \\
C_{\text {ori }}, \text { c.u. }\end{array}$ & $\begin{array}{c}\text { Safety stock } S_{Q}, \\
\text { un. }\end{array}$ & Holding costs, $\mathrm{C}_{\mathrm{hi}, \text { c.u. }}$ & $\begin{array}{c}\text { Total costs, } \sum\left(C_{\text {ori }}+C_{\text {hi }}\right), \\
\text { c.u. }\end{array}$ \\
\hline 1 & 50 & 1200 & 5 & 10 & 1210 \\
\hline 2 & 70 & 1200 & 6,5 & 13 & 1213 \\
\hline 3 & 80 & 1200 & 7 & 14 & 1214 \\
\hline 4 & 60 & 1200 & 6 & 8 & 1212 \\
\hline 5 & 40 & 1200 & 4 & 14 & 1214 \\
\hline 6 & 75 & 1200 & 7 & 10 & 1210 \\
\hline 7 & 45 & 1200 & 5 & 12 & 1212 \\
\hline 8 & 60 & 1200 & 6 & 93 & 9693 \\
\hline Sums & 480 & 9600 & & & \\
\hline
\end{tabular}


Table 4. Consignments quantity evaluation based on POQ (Period Order Quantity) strategy

\begin{tabular}{|c|c|c|c|c|c|c|c|}
\hline Week & $\begin{array}{c}\text { Planned need, } \\
\mathrm{N}_{\mathrm{i}} \text {, un. }\end{array}$ & $\begin{array}{c}\text { Number of weeks } \\
\text { in the periode }\end{array}$ & $\begin{array}{c}\text { Order costs, } \\
C_{\text {ori }}, \text { c.u. }\end{array}$ & $\begin{array}{c}\text { Current stock } \\
\text { holding costs, c.u. }\end{array}$ & $\begin{array}{c}\text { Safety } \\
\text { stock, un. }\end{array}$ & $\begin{array}{c}\text { Safety stock } \\
\text { holding costs, c.u. }\end{array}$ & $\begin{array}{c}\text { Total } \\
\text { costs, c.u. }\end{array}$ \\
\hline 1 & 50 & 1 & 1200 & 0 & 5 & 10 & 1210 \\
\hline 2 & 70 & $1-2$ & 0 & 140 & 10 & 40 & 170 \\
\hline 3 & 80 & 1 & 1200 & 0 & 7 & 14 & 1214 \\
\hline 4 & 60 & $1-2$ & 0 & 120 & 11 & 44 & 150 \\
\hline 5 & 40 & 1 & 1200 & 0 & 4 & 8 & 1208 \\
\hline 6 & 75 & $1-2$ & 0 & 150 & 10 & 40 & 182 \\
\hline 7 & 45 & 1 & 1200 & 0 & 5 & 10 & 1210 \\
\hline 8 & 60 & $1-2$ & 0 & 120 & 8 & 32 & 142 \\
\hline Sums & 480 & & 4800 & 530 & & 156 & 5486 \\
\hline
\end{tabular}

Table 5. Consignments quantity evaluation based on LTC (Least Total Cost) strategy

\begin{tabular}{|c|c|c|c|c|c|c|c|c|}
\hline \multirow{2}{*}{$\begin{array}{l}\text { Number of } \\
\text { weeks in the } \\
\text { period }\end{array}$} & \multirow{2}{*}{$\begin{array}{l}\text { Planned } \\
\text { need, un. }\end{array}$} & \multirow{2}{*}{$\begin{array}{l}\text { Production } \\
\text { volume, un.. }\end{array}$} & \multirow{2}{*}{$\begin{array}{c}\text { Order } \\
\text { costs, } \\
\text { c.u. }\end{array}$} & \multirow{2}{*}{$\begin{array}{c}\text { Order } \\
\text { quantity, } \mathrm{k}\end{array}$} & \multicolumn{2}{|c|}{ Stock holding costs, c.u. } & \multirow{2}{*}{$\begin{array}{l}\Delta_{k}= \\
=\left|C_{o r}-C_{h}^{*}\right|\end{array}$} & \multirow{2}{*}{$\begin{array}{c}\text { Total costs, } \\
\text { c.u. }\end{array}$} \\
\hline & & & & & current & safety & & \\
\hline 1 & 50 & 300 & 1200 & 50 & 0 & 10 & 1190 & 1210 \\
\hline 2 & 70 & 0 & 0 & 120 & 140 & 40 & 1020 & 1380 \\
\hline 3 & 80 & 0 & 0 & 200 & 460 & 90 & 650 & 1750 \\
\hline 4 & 60 & 0 & 0 & 260 & 820 & 152 & 228 & 2172 \\
\hline 5 & 40 & 0 & 0 & 300 & 1140 & 213 & $|-153|$ & 2553 \\
\hline 1 & 75 & 180 & 1200 & 75 & 0 & 14 & 1186 & 1214 \\
\hline 2 & 45 & 0 & 0 & 120 & 90 & 40 & 1070 & 1330 \\
\hline 3 & 60 & 0 & 0 & 180 & 330 & 84 & 786 & 1614 \\
\hline
\end{tabular}

Table 6. Consignments quantity evaluation based on LUC (Least Unit Cost) strategy

\begin{tabular}{|c|c|c|c|c|c|c|c|c|}
\hline \multirow{2}{*}{$\begin{array}{l}\text { Number of } \\
\text { weeks in } \\
\text { the period }\end{array}$} & \multirow{2}{*}{$\begin{array}{l}\text { Planned } \\
\text { need, un. }\end{array}$} & \multirow{2}{*}{$\begin{array}{l}\text { Production } \\
\text { volume, un. }\end{array}$} & \multirow{2}{*}{$\begin{array}{l}\text { Order } \\
\text { costs, } \\
\text { c.u. }\end{array}$} & \multirow{2}{*}{$\begin{array}{l}\text { Remained } \\
\text { stock, un. }\end{array}$} & \multicolumn{2}{|c|}{ Stock holding costs } & \multirow{2}{*}{ Total costs, c.u. } & \multirow{2}{*}{$\begin{array}{l}\text { Specific costs, } \\
\text { c.u. }\end{array}$} \\
\hline & & & & & current & safety & & \\
\hline 1 & 50 & 260 & 1200 & 210 & 0 & 10 & 1210 & 24,2 \\
\hline 2 & 70 & 0 & 0 & 140 & 140 & 40 & 1380 & 11,5 \\
\hline 3 & 80 & 0 & 0 & 60 & 460 & 90 & 1750 & 8,75 \\
\hline 4 & 60 & 0 & 0 & 0 & 820 & 152 & 2172 & 8,35 \\
\hline 1 & 40 & 220 & 1200 & 180 & 0 & 8 & 1208 & 30,2 \\
\hline 2 & 75 & 0 & 0 & 105 & 150 & 40 & 1390 & 12,1 \\
\hline 3 & 45 & 0 & 0 & 60 & 330 & 78 & 1598 & 9,98 \\
\hline 4 & 60 & 0 & 0 & 0 & 690 & 128 & 2018 & 9,20 \\
\hline
\end{tabular}

Table 7. Total costs and reliability indexes calculation results for different inventory management strategies (dependent demand)

\begin{tabular}{|l|c|c|c|c|}
\hline \multirow{2}{*}{ Strategy } & \multicolumn{2}{|c|}{ Total costs, c.u. } & \multicolumn{2}{c|}{ Probabilities } \\
\cline { 2 - 5 } & Without considering the safety stock & Considering the safety stock & $\begin{array}{c}\text { Without considering } \\
\text { the safety stock }\end{array}$ & $\begin{array}{c}\text { Considering the } \\
\text { safety stock }\end{array}$ \\
\hline LFL & 9600 & 9693 & 0,663 & 0,980 \\
\hline POQ & 5330 & 5486 & 0,814 & 0,990 \\
\hline EOQ & 4293 & 4464 & 0,903 & 0,995 \\
\hline LTC & 3870 & 4167 & 0,903 & 0,995 \\
\hline LUC & 3910 & 4190 & 0,903 & 0,995 \\
\hline
\end{tabular}

The analysis of obtained results allows making the following conclusions:

1. Total costs calculated on the basis of the empiric strategies (LFL, POQ) are significantly larger than the same costs calculated on the basis of the economic strategies (EOQ, LTC, LUC).

2. The best strategy in view of total costs minimum criterion is LTC strategy: this conclusion coincides with the results of (Chase et al., 1998) and (Leenders and Fearon, 1997) works.

3. The consideration of safety stock holding costs (for given example) results in increasing the total costs from $1 \%$ (LFL) to $7 \%$ (LTC).

4. Calculation results using the LTC strategy and Silver-Meal algorithm are the same.

5. There is a stable relationship between the safety stock holding costs and supply reliability indexes: the supply reliability probability increase requires the safety stock costs increase. 


\section{Further Research Directions}

The suggested methodical approach belongs to the stage of dependent demand stocks planning. When it is fulfilled in practice, the planned quantity of safety stocks will differ from actual values of stocks consumption (due to the probabilistic patterns used for their calculations). Therefore, at the beginning of every new consignment (that lasts one or several weeks) it is necessary to check and correct the planned values considering the rests of previous period (probably, using the prediction methods), i.e., actually, here we are speaking about the use of situational approach to manage stocks at dependent demand.

The significant disadvantage of these strategies is the assumptions of fixed costs for supply or starting-up and adjustment works. Apparently, they should be clarified depending on the supply quantity. So, in the examined example, the costs for one-week supplies of 50 units (LFL strategy) and for a five weeks period of 300 units (LTC strategy) are identical.

The reason for great variations of total costs quantity is that for the consignments which arrive at the manufacture directly, the costs for current stock holding aren't considered; the only exception is EOQ strategy (which considers these holding costs).

The precision and accuracy of supply planning on the basis of worked out method can be proved according to the results of various variants modelling of actual costs, costs considering methods and so on, from one hand. From the other hand, the final conclusions can be made according to the results of approbation at the real production conditions. The modelling results analysis and summarizing and the approbation will enable us to make a definite variant of choosing method of optimal IM strategy at dependent demand which will allow increasing the efficiency and reliability of supply chains.

\section{References}

1. Axsäter, S. (2006) Inventory control. 2nd ed,. New York: Springer Science + Business Media.

2. Ballou, R. (1999) Business logistics Management. New York: Prentice-Hall International, Inc.

3. Chase, R., Aquilano, N., Jacobs, F. (1998) Production and operations management. $8^{\text {th }}$ ed. Irvin, McGraw-Hill Companies, Inc.

4. Christopher, M. (2011) Logictics and supply chain management. 4th ed. Harlow: Pearson Education Limited

5. Coyle, J., Bardi E., Langley C. (2003) The Management of Business Logistics: A Supply Chain Perspective, 7 th ed., South-Western Thomson Learning.

6. Heizer, J., Render, B. (2011) Operations Management. 10th ed. Edinburgh Gate Harlow England: Pearson Education Limited.

7. Jonsson, P. (2008) Logistics and Supply Chain Management. UK: McGraw-Hill Companies, Inc.

8. Krajewski, L., Ritzman, L., Malhotra, M. (2013) Operations Management, Processes and Supply chains. 10th ed. Upper Saddle River, New Jersey: Pearson Education Limited.

9. Leenders, M., Fearon, H. (1997) Purchasing and Supply Management (11th ed.). Chicago, Illinois, USA: Irwin.

10. Lukinskiy, V.S., Lukinskiy V.V. (2015) Formation of failure models for the evaluation of the reliability of supply chains. Transport and Telecommunication, 16 (1), 40-47. DOI 10.1515/ttj-20150005 .

11. Lysons, K., Gillingham, M. (2003) Purchasing and supply chain management. London: Prentice Hall.

12. Stadtler H., Kilger C., (2008) Supply Chain Management and Advanced Planning. Concepts, Models, Software, and Case Studies. 4th ed., Springer-Verlag Berlin Heidelberg.

13. Stock, J.R., Lambert, D.M. (2001) Strategic Logistics Management. 4th ed. Boston: McGraw-Hill Irwin.

14. Ventsel, E.S., Ovcharov L.A. (1983) Applied problems of probability theory. Moscow: Radio and communications. (In Russian)

15. Wisner, J., Tan, K., Leong, G. (2012) Supply Chain Management: A Balanced Approach, 3th ed. South-Western, Cengage Learning. 